\title{
A privileged association with Satish Dhawan
}

\author{
T. S. Prahlad* \\ Former Director, CSIR-National Aerospace Laboratories, Benglauru 560 017, India
}

\begin{abstract}
On this occasion of the Birth Centenary of Satish Dhawan, I am happy to recall my association with him for nearly four decades. It started as a Master's and PhD student in the Department of Aeronautical Engineering, Indian Institute of Science, Bengaluru under his guidance. The association continued when I moved over as an engineer to the Vikram Sarabhai Space Centre (ISRO), Thiruvananthapuram and Dhawan took charge, around the same time, as Chairman of ISRO. I had the privilege of being a member of National Aerospace Laboratories' (NAL's) Research Council when he was its Chairman. Later, I was the benefactor of his immense goodwill and generous advice when I became Director of NAL. I consider this association with Dhawan a great privilege of my life.
\end{abstract}

\section{Introduction}

THIS article briefly mentions about some of the reminiscences of the author when he was closely associated with Satish Dhawan at Indian Institute of Science (IISc), Bangalore at the Vikram Sarabhai Space Centre (VSSC) of the Indian Space Research Organisation (ISRO) and at National Aerospace Laboratories (CSIR-NAL), Bangalore.

\section{Department of Aeronautical Engineering, IISc}

I joined the Department of Aeronautical Engineering, IISc, as a Master's student in 1961 when Dhawan was already Chairman of the Department at the age of 41. My seniors talked about him with undisguised awe and admiration because of his expertise in fluid mechanics, and the pioneering work he had done at Caltech, USA. He was an exuberant, charismatic, cheerful and inspiring personality - very friendly and informal with students. He was an excellent teacher; I recall with pleasure the aerodynamics course he taught our batch - so full of physical insight, and with precise and beautifully prepared teaching material. The oral examinations the faculty used to conduct at the end of each semester was special if Dhawan was present to ask simple but penetrating questions.

After finishing our Master's course in 1963, there was discussion among my classmates on what to do next. Some of us wanted to stay back at IISc to do our PhD.

\footnotetext{
*e-mail: tumkur_prahlad@yahoo.com
}

Dhawan had already become Director of IISc at the age of 42, and was quite busy. After some trepidation, I walked into the Director's Office one day to request him to take me as his $\mathrm{PhD}$ student. After barely a minute of thinking, he agreed and said I should work on threedimensional turbulent boundary layers, a topic of considerable relevance to the aeronautical industry because of low aspect ratio wings, blended aircraft configurations and high-performance gas turbines. I suspect one of the reasons Dhawan so readily agreed to take me as his $\mathrm{PhD}$ student was that he did not want to be totally lost in the management and administrative duties of the Director.

My work was supposed to be mainly experimental to be conducted in the Department's $2 \mathrm{ft} \times 2 \mathrm{ft}$ boundary layer wind tunnel which had already produced excellent research dissertations. It was the general practice in the Department that research students build their own instrumentation required for their experimental investigations. My work involved, to start with, measurement of threedimensional skewed boundary layer profiles and threedimensional skin friction magnitude and direction (Figure 1). Dhawan's work at Caltech on direct measurement of skin friction using a floating element balance was already well known. We dabbled with the idea of building a similar instrument for three-dimensional flows, but quickly found that pressure gradients across the floating element posed an accuracy problem. We finally settled for indirect measurement of skin friction using twin Preston and Stanton tubes - two tubes joined together and both chamfered back at equal angles to obtain skin friction direction, the magnitude being obtained by the reading of one

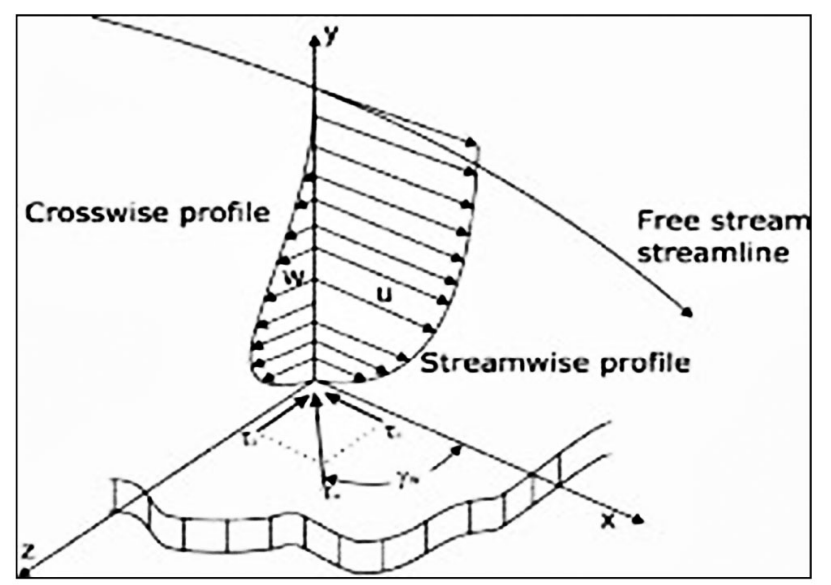

Figure 1. Three-dimensional boundary layer and skin friction vector. 
of the tubes calibrated against skin friction in a rectangular channel ${ }^{1}$. A three-dimensional boundary layer field was created by a body mounted on a flat plate and the three-dimensional boundary layer velocity vector at each vertical position was obtained by an essentially similar procedure at various locations of the boundary layer field $^{2}$. A three-dimensional boundary layer traverse was designed and built to do the boundary layer survey along with other probes like five-hole pitot probes, disc static pressure probes, etc.

In all this, Dhawan's expertise in building delicate instrumentation was of great help. Whenever he could take a little time off from the Director's Office, he used to come down to the laboratory housing the boundary layer tunnel and we used to walk down to the workshop which had some remarkable mechanics who could build almost anything we wanted. It was exciting to watch Dhawan giving precise instructions to these mechanics and urging them to excel in producing accurate instrumentation needed for good experimental work.

Dhawan got busier and getting his time for serious discussions was not always easy. It was a pleasure whenever I could find a slot and I always came back with renewed enthusiasm and vigour. My first paper submitted to AIAA Journal on wall similarity in three-dimensional turbulent boundary layers was written rather clumsily ${ }^{3}$. He patiently brought it to a good shape and declined to have his name added to the paper. Dhawan continued to walk into the laboratory unexpectedly with new ideas. But I quickly learnt that I had to sift through those ideas with an eye on the days that were rolling by. Though I got to be mostly on my own as the work progressed, the guide was always there if I needed any help. It was a nice feeling of independence as well as support.

After my PhD work took reasonable shape, I joined the faculty of Department of Aeronautical Engineering, IISc, first as Technical Assistant and then as Lecturer, and helped in wind tunnel testing and some lectures on boundary layer theory. The solid background given to us by Dhawan and other senior faculty members was helpful.

I had personal problems during the closing part of my thesis work, as my father was seriously ill with liver cancer. I can never forget the moral support I got from Dhawan. He constantly enquired about my father's health and sent one of the professors to our home to talk to us about chemotherapy. When my father expired, a small note received in typical Dhawan style was a source of great strength to me (Figure 2).

\section{Vikram Sarabhai Space Centre, ISRO}

After completing my theoretical and experimental work for $\mathrm{PhD}$, I joined VSSC/ISRO in 1970, even before I wrote and submitted my thesis at IISc. As I was initially posted in Bengaluru itself to take care of wind tunnel testing activities for VSSC, I could maintain my association with Dhawan and IISc which was a great help in writing up my thesis.

In 1972, Dhawan himself joined ISRO as its Chairman after the untimely demise of its founder Chairman Vikram Sarabhai, even as he continued as Director of IISc. The requests he had made of having the ISRO Headquarters at Bengaluru and a Space Commission structure for the management of ISRO had been accepted. The major launch vehicle project at that time at VSSC/ ISRO was SLV-3 which, it seemed to me, was being

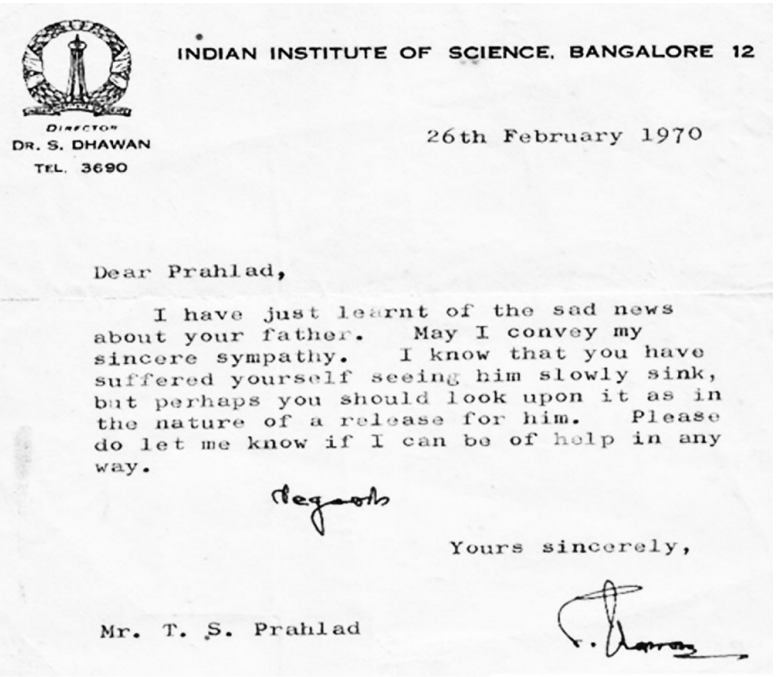

Figure 2. Dhawan's note when my father expired.

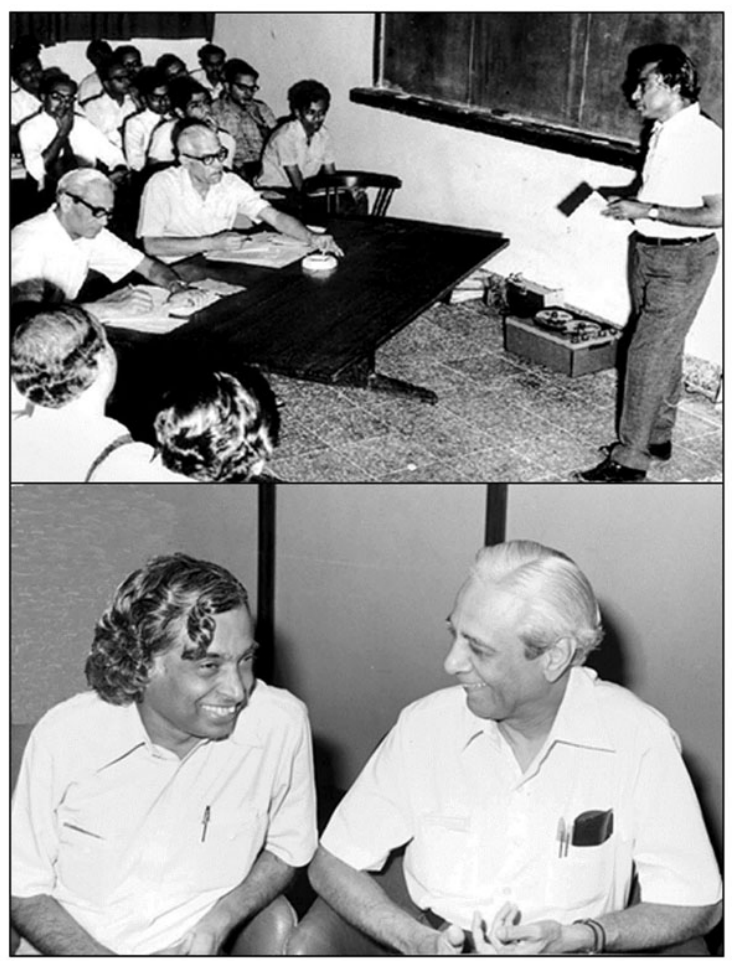

Figure 3. Close rapport between Dhawan and Kalam.

CURRENT SCIENCE, VOL. 119, NO. 9, 10 NOVEMBER 2020 


\section{SATISH DHAWAN BIRTH CENTENARY}

tackled till then in a fragmented fashion with different leaders for different aspects of the project. The first thing Dhawan did was to bring in the noted metallurgist Brahm Prakash as the Director of VSSC and to create a unified project leadership for SLV-3 under A. P. J. Abdul Kalam, already known as a hard working go-getter and teambuilder. Dhawan and Kalam had a good personal rapport and high regard for each other, which greatly helped in the progress of the project (Figure 3). The remarkable contribution made by Kalam to aerospace programmes in the country over the years bears testimony to the sharp judgement of Dhawan in recognizing leadership qualities of people. He always projected Kalam as the main force behind the SLV-3 project.

For me, it started another long period of association with Dhawan even though he held the topmost position in ISRO, while I was a somewhat junior engineer. This was especially so after I moved to VSSC, Thiruvananthapuram in the beginning of 1975, after spending two years on leave from VSSC at University of Cambridge, UK, as a postdoctoral fellow. The SLV-3 project by then was on a much stronger footing with a good management structure of tasks and responsibilities, and with a strong urge and commitment to succeed even though we were building a satellite launch vehicle for the first time.

One of the most important traditions Dhawan introduced early on was the system of peer technical reviews for each important aspect of the SLV-3 project/ technology wherein well-known experts in that discipline from all over the country - from academia, R\&D organizations, industry, etc. - were invited and ISRO engineers had to make structured presentations of their work, often after submitting written documentation. I remember there were misgivings about this among some of the ISRO engineers, based on the feeling that the external peer reviewers could not completely appreciate the details and intricacies of what is really involved in the particular project task or the associated technology. But soon everybody began to appreciate the usefulness of the exercise in terms of the clarity of thinking that came out of the efforts put in preparing good documentation, defending one's approach to the problem and putting it across in a structured fashion, not to speak of the fresh ideas that came out from some of the reviewers. This has now become a standardized and cherished culture of ISRO, and I consider this to be one of the most notable contributions of Dhawan.

The high peak of these peer reviews was the two to three day review by the Chairman of ISRO, along with a few selected external experts, on the progress and status of the major projects SLV-3. One of the extraordinary aspects about these reviews was that it was open to all the engineers of VSSC and at the end of a presentation or during discussion sessions, anybody could stand up to ask a question, seek a clarification or provide an explanation. Dhawan always encouraged this and it considerably nar- rowed down the distance between the topmost management of ISRO and its working-level staff. During such review periods, Dhawan used to carve out a time where he wanted to listen to some scientific or technological aspect in much greater detail. One such particular session I remember was the presentations on 6-D trajectory optimization by three VSSC engineers using three different approaches - starting at $9 \mathrm{pm}$ after dinner and going past midnight. This was the scientist/professor in the Chairman of ISRO which we loved.

Like any complex project, SLV-3 had its technical problems when we saw the leader and manager in Dhawan. One such was the failure of the rocket nozzle in the static test on SLV-3 first-stage motor at Sriharikota static test complex. In order to address the underlying nozzle flow and heat transfer design issues, he set up an independent review committee with R. Narasimha as Chairman, members from the concerned design team and me as the convener, though I was not directly connected with nozzle design. We had exhaustive discussions in the committee on the design procedures followed. VSSC had conducted static tests on a number of subscale motors, and I was asked to look into the results from these tests to assess what lessons we could learn from them. Using simple heat-transfer parameters like Biot number $B_{i}$ and Fourier number $F_{0}$, a one-parameter family of curves was established for char depth ratio $\delta_{c} / \delta$ (representing the safety margin, where $\delta$ is the initial ablative liner thickness and $\delta_{c}$ is the thickness of the layer that is charred due to nozzle flow heat transfer). This was done for both the combined carbon phenolic and silica phenolic ablative liners used in the nozzle fore-end, and the silica phenolic liner used in the aft end ${ }^{4}$.

These parametric curves reproduced experimental data of ablative liner charring within plus or minus $15 \%$ (Figure 4). The chief merit of this approach was that a new or a bigger nozzle ablative liner could be designed based on our own static test database, rather than literature values. The results were presented to Dhawan in the next project review and he was happy as he liked such simple engineering approaches to problem-solving.

The close association between Dhawan and Kalam and his team throughout the SLV-3 days was something we all watched with admiration (Figure 5). Kalam has recounted many a time how Dhawan stood by him when the first SLV-3 launch on 10 August 1979 was unsuccessful, and how he gave him full credit when the second launch on 18 July 1980 was a success. Those of us who were in VSSC during that period surely learnt a great lesson from this.

After the successful SLV-3 launch, Kalam was moved as Director of a technical group - Aerospace Dynamics and Design and thus became my direct boss as I was in the Aerodynamics Division. The SLV-3 continuation, and the follow-on projects of Augmented Satellite Launch Vehicle (ASLV) and the Polar Satellite Launch Vehicle 
(PSLV) were put under three different younger Project Directors, with Kalam always being available as a senior advisor. I consider this management strategy initiated by Dhawan and being followed by ISRO, to be a great contributor in ISRO's continued success as there has always been smooth transition and never a leadership crisis in ISRO.

Another high point of my association with Dhawan on launch vehicle projects at VSSC was the configuration finalization of the PSLV. Mainly two configuration options were under discussion. One was a 125-tonne solid rocket motor assisted by six 9-tonne solid rocket strap-on boosters derived from SLV-3 as the first stage of PSLV, a 37.5-tonne liquid propellant second stage, a 7-tonne solid third stage and a 2-tonne liquid fourth stage to obtain required orbital injection accuracy. Another was to have the first stage as an 80-tonne solid propellant motor strapped

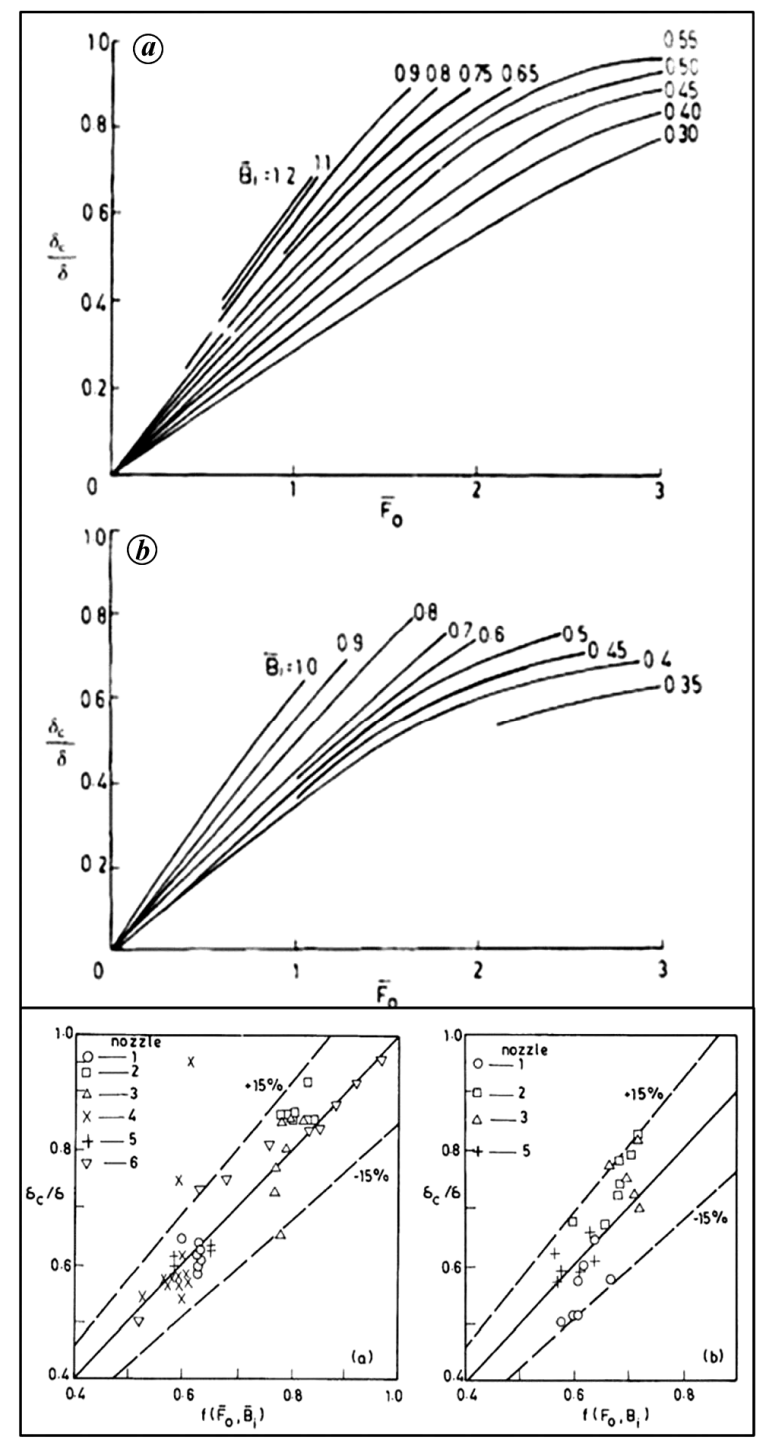

Figure 4. Correlation of char depth in ablative liners: $\boldsymbol{a}$, Carbon phenolic + silica phenolic; $\boldsymbol{b}$, silica phenolic alone. on with two 80-tonne solid propellant boosters. There were advantages and disadvantages of each configuration, and Dhawan was keen that we analyse them critically so that a right decision was made, so crucial for the future of ISRO. As Head of the Aerodynamics Division and assisted by my team for such configuration studies, I made a number of presentations to Dhawan and other

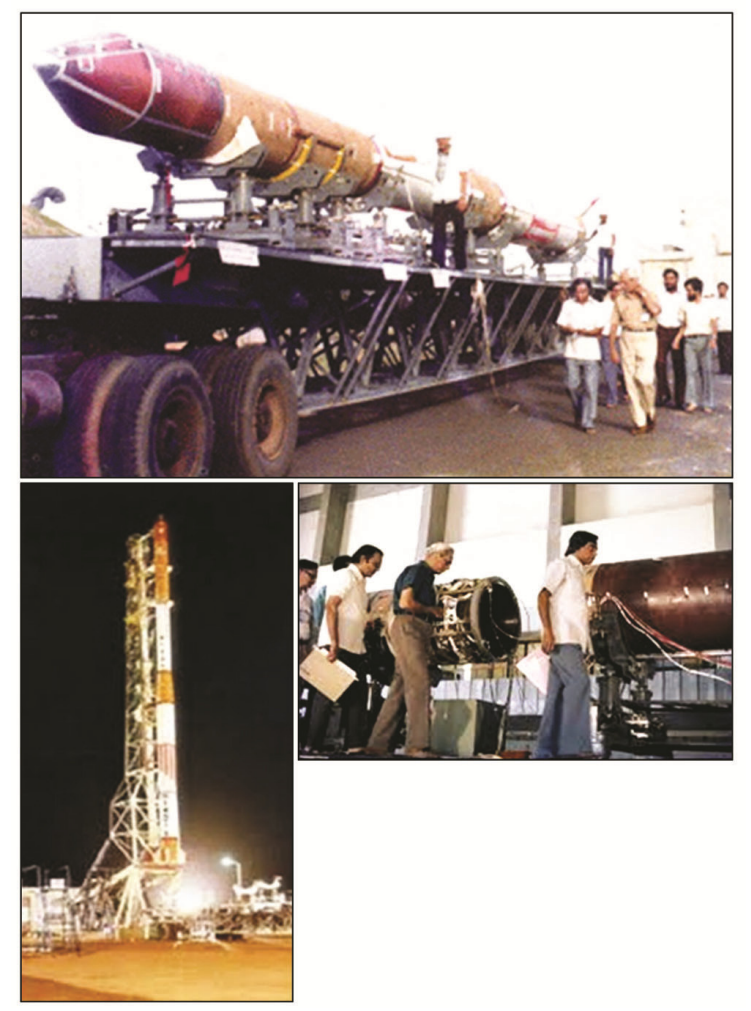

Figure 5. Dhawan with SLV-3 team during launch preparation.

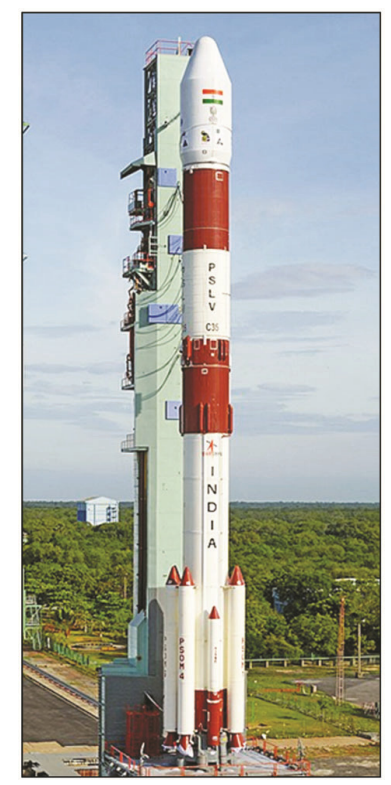

Figure 6. PSLV configuration after detailed deliberations.

CURRENT SCIENCE, VOL. 119, NO. 9, 10 NOVEMBER 2020 


\section{SATISH DHAWAN BIRTH CENTENARY}

senior people, both at VSSC and at ISRO Headquarters, bringing out the specific features of each configuration. Aided by further studies by Kalam and his team at the ISRO Headquarters, Dhawan finally took a decision that the basic PSLV configuration should have a 125-tonne solid rocket first stage aided by six SLV-3 S1 strap-on boosters (Figure 6). In retrospect, this was a momentous decision considering the continued success of the basic PSLV and its variants, and rightfully earning the name as the workhorse of ISRO launches.

As liquid propulsion upper stage was essential for PSLV and ISRO did not fully have this technology at that time, Dhawan deputed an ISRO team to work with a French team when they were developing the Viking engine for the Ariane launch vehicle of the European Space Agency. The ISRO team came back and successfully built the liquid second stage of PSLV. This, I consider, was a brilliant management strategy to leapfrog in the technological progress of ISRO and can be followed by other high-technology initiatives of the country.

Dhawan often used to pose certain out-of-the-routine challenges to ISRO engineers. One such with which I was associated was to predict the date, time and impact location of Skylab, the first space station of USA launched in 1973 and expected to re-enter into the earth's atmosphere sometime in July 1979. In spite of many uncertainties like correct orbital parameters, effects of tumbling motion, different modes of structural break up, etc. we made a reasonable prediction of Skylab's impact on 11 July in the Indian Ocean away from the sub-continent, which

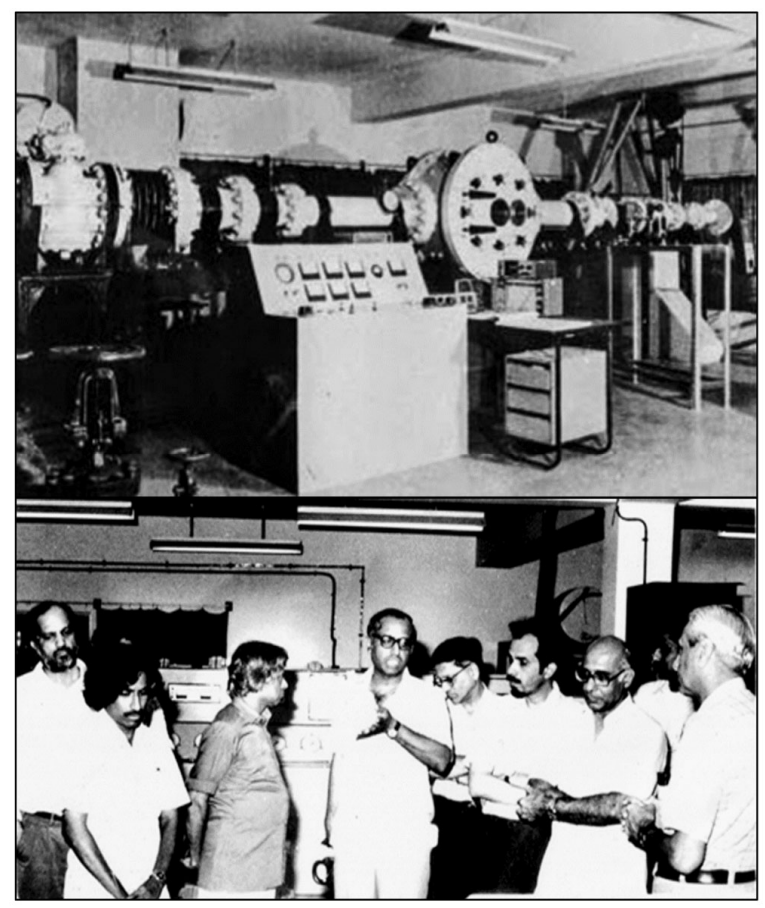

Figure 7. The first hypersonic tunnel of VSSC and visit of Dhawan and the review team to the facilities. turned out to be broadly correct. Perhaps, Dhawan wanted to test how much we understood a complex subject like re-entry dynamics which would be required one day for ISRO's missions.

Apart from problems associated with launch vehicle projects, my interactions with Dhawan when I was at VSSC also included issues connected with fluid mechanics and wind tunnel design and testing - topics of common interest to both. The aerodynamic research done at VSSC at that time under his overall leadership has been summarized in an issue of Sadhana ${ }^{4}$, brought out in honour of Dhawan. One particular incident I recall was his support for our building the 10-inch free jet Mach number 4 to 8 hypersonic blow-down wind tunnel in 1980 , the first in the country. We had made considerable progress and wanted another Rs 2 lakhs to complete the project. After some thinking because of tight funding

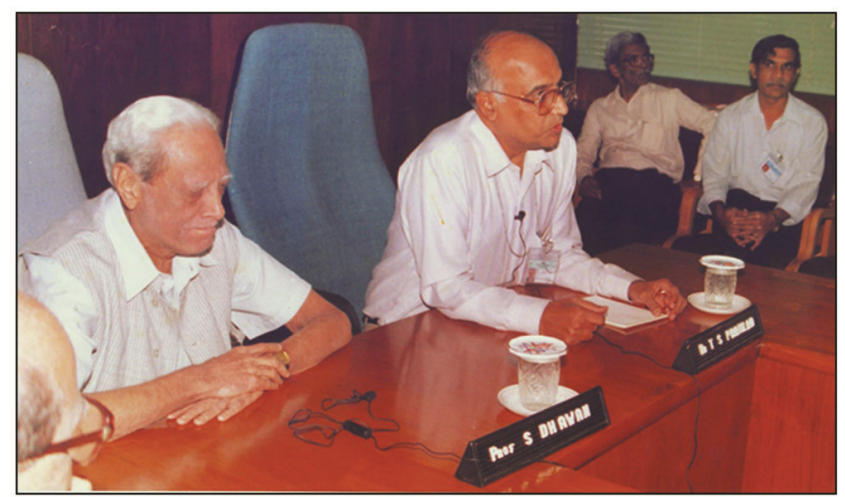

Figure 8. Dhawan during one of his visits to NAL, Bengaluru.

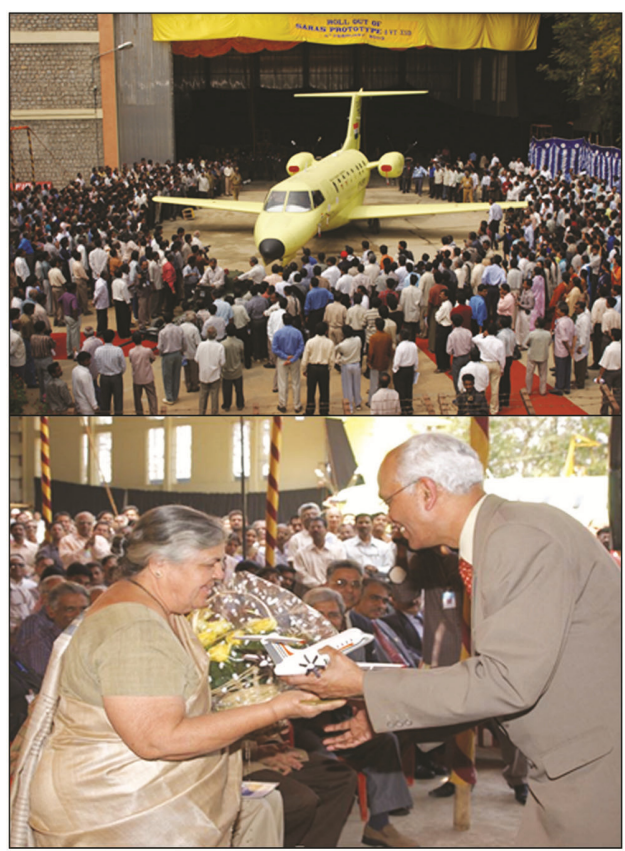

Figure 9. SARAS roll-out in February 2003 and DG-CSIR R. A., Mashelkar presenting a model of SARAS to Nalini Dhawan. 


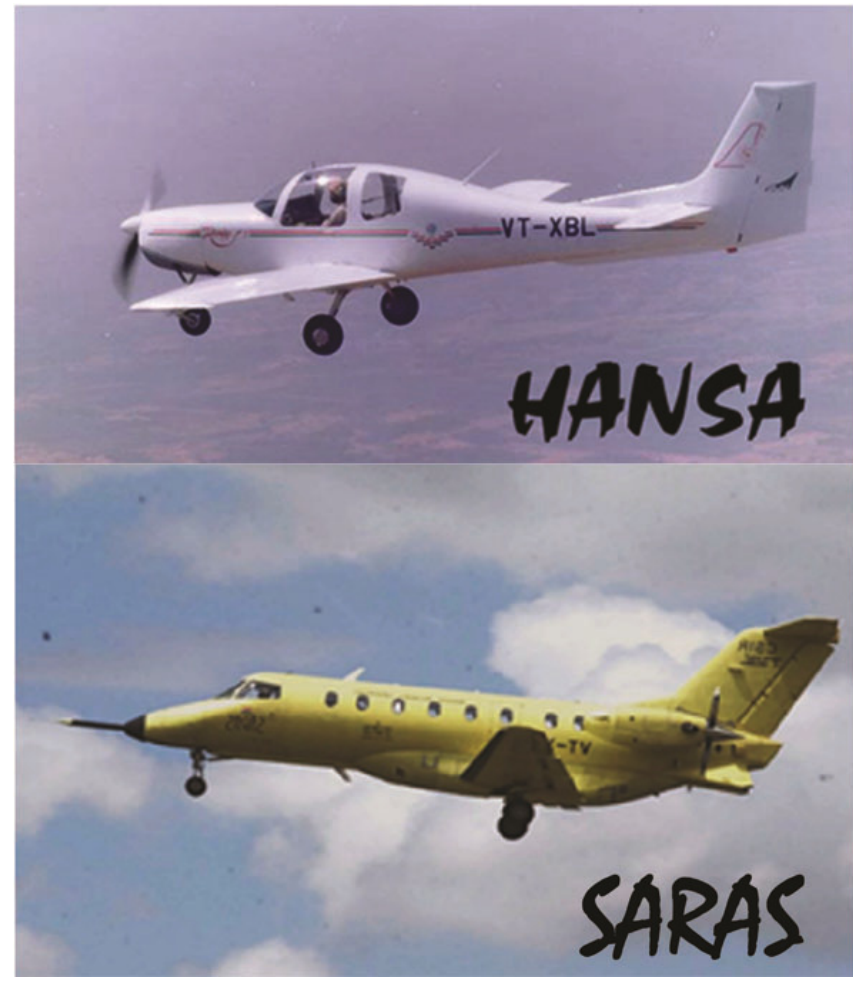

Figure 10. HANSA and SARAS in flight $-\mathrm{a}$ tribute to the vision of Dhawan.

constraints at that time, Dhawan agreed to provide the funding, but with the condition that we should make the first blow-down within the next one year. The condition was accepted and during his visit to VSSC within a year, I presented a schlieren picture of the first hypersonic blow-down. After a detailed review of the activities of the Aerospace Dynamics and Design Group which Kalam had organized on a later date, Dhawan and other specialists visited the Laboratory to look at the Hypersonic Wind Tunnel and other facilities (Figure 7). It was fun as well as a challenge to work with Dhawan and we all enjoyed it.

In summary, Dhawan provided great leadership to ISRO when it was most required and it was my privilege to watch it from close quarters.

\section{Aeronautical Development Agency and National Aerospace Laboratories}

At the beginning of 1987, I moved to Aeronautical Development Agency (ADA), a unit of the Department of Defence R\&D, specifically set up for the Light Combat Aircraft (LCA) project in India. After his retirement from DoS in 1984, completing 12 momentous years of its stewardship, Dhawan was still associated with many aerospace activities in the country, one of them being the Chairmanship of the Research Advisory Council (RAC) of CSIR-NAL. I was a member of this Council when I was at VSSC, and I continued to be a member even after I joined ADA. I was highly impressed by his thorough preparation for these Council meetings, his getting into details of the work of the scientists and the frank discussions he used to encourage among the Council members. Perhaps the most notable contribution the RAC made under his leadership was to exhort that 'NAL should initiate a major thrust in civil aviation by identifying areas where opportunities exist in India, develop and integrate civil aviation products including aircraft and chart a blueprint and strategy for establishing a vibrant civil aviation industry'. This was indeed a momentous recommendation as, NAL with its years of aeronautical research and development background, was quite well poised to take up actual aircraft product development activity on a modest scale. Thus were born the two-seater all composite trainer aircraft HANSA and 14-seater lighttransport aircraft SARAS programmes under the leadership of the then NAL Director Narasimha.

After working in ADA for nine years, I joined NAL as its fifth Director in May 1996. U. R. Rao sometime had taken over as the Chairman of the Research Council. I used to maintain contact with Dhawan to brief him about the important activities going on at NAL, and he also used to visit us once in a while (Figure 8). One of my main tasks was to push the design and development of the 14-seater SARAS, which had taken considerable time for getting the necessary approval, with funding from the Government actually coming only in September 1999. 
Unfortunately, Dhawan was no more with us when the first flight of SARAS took place on 29 May 2004. In recognition of the inspiration Dhawan had provided to this activity, NAL thought it highly appropriate to give the registration number of the first SARAS prototype as VT-XSD, SD standing for Satish Dhawan. A grateful NAL presented a model of SARAS during its rollout ceremony in February 2003 to Nalini Dhawan (wife of Satish Dhawan) who was a great source of support to him throughout his illustrious career (Figure 9). HANSA and SARAS bear testimony to the vision of Dhawan in initiating in a small way civilian aircraft design and development in the country (Figure 10).

\section{Final remark}

Dhawan's contribution to the Indian aerospace was manyfold. He was an excellent teacher and an inspiring guide. He laid the foundation of experimental fluid mechanics in India with important contributions to many areas like two-dimensional and axisymmetric boundary layer transition and turbulence, boundary layer displacement effects, turbulent wall jets, base flows, reverse transition, laminar separation bubbles, three-dimensional turbulent boundary layers, etc. He designed and developed several high-speed facilities and associated instrumentation in IISc.

Equally important, if not more, was the positive and inspiring leadership Dhawan provided to both IISC and ISRO with which he was associated for fairly long periods. In many ways, he transformed the character and culture of ISRO and built systems which have contributed a great deal towards its continuing success. Most important of all is Satish Dhawan the person - charming, informal, meticulous, friendly and humane with everybody around him. Perhaps this is what all those who knew him cherish the most.

1. Prahlad, T. S., Yaw characteristics of Preston tubes. AIAA J., 1972, 10, 357-359.

2. Prahlad, T. S., Mean velocity profiles in three dimensional turbulent boundary layers. AIAA J., 1973, 11, 359-365.

3. Prahlad, T. S., Wall similarity in three dimensional turbulent boundary layers. AIAA J., 1968, 6, 1772-1774.

4. Prahlad, T. S., A profile of aerodynamic research in VSSC with application to satellite launch vehicles. Sadhana, 1988, 12, 125-182.

doi: $10.18520 / \mathrm{cs} / \mathrm{v} 119 / \mathrm{i} 9 / 1433-1439$

\section{Satish Dhawan (25 September 1920-3 January 2002)}

1. I have been an admirer of Prof. Satish Dhawan. I am not saying so just because we have been morally on same side. He has been a gentle giant of things to come. He was a moving force to me, and I lost one of my brethren. He was charming throughout and a lover of mankind. I miss him badly. He was a moral force.

2. His gentle ways of handling employees' problems were extraordinary and never done before. He brought an upswing in the faculty recruitment. The age old curriculum needed doing a lot of brushing up.

3. He was a Professor, Director, and Chairman, ISRO, often multitasking.

4. He was gentle at heart. I have missed him so badly.

May his soul rest in peace. 